\title{
EFFECTIVE STUDY HABITS IN EDUCATIONAL SECTOR: COUNSELLING IMPLICATIONS.
}

\author{
OGBODO, Rosemary Ochanya PhD \\ Continuous Education \\ FCT College of Education \\ Zuba. Abuja \\ email: rosemaryochanyaogbodo@yahoo.com
}

\begin{abstract}
The problem most students have that contributes to their poor performance in tests and examination is lack of proper study habit. For an excellent performance, there is need for the student to form good study habit. A student, who wants to study well, needs to choose a suitable place for his studies. Where to study is as important as what to study and how to go about studying. Productive study habits require learners to prepare personal time-table for themselves allocating a certain length of time for a particular subject, depending on how difficult each subject is. Different methods of studying are well explained here.
\end{abstract}

Key Words: Counselling, Study habits, Reading habits, Education

\section{Introduction}

In School, high academic performance has been attributed to students' effective study habits. This is the reason why the teacher tries to adopt many techniques to help the students to learn. There will be a brief explanation of the topic, followed by the need for planning effective study habit programme. A description of the typology of study habits will be supported by recommendation for techniques of effective study habits. The counsellor's role in the formation of study habits will form the concluding section.

The learner's Dictionary has defined study as a "mental effort to obtain knowledge ". This means that studying is an art of learning which helps the individual not only to acquire knowledge but also the skill and the habit to study. Narramore (1974) defined habit as "a pattern of activity which, through repetition, has been learned to the point that it has become automatic and can be carried on with a minimum of conscious effect". Effective study habit refers to a situation in which a 
learner studies regularly to achieve maximum success in his school work. Study habit, therefore, refers to learning which leads to the achievement of a learner's goal, through a prescribed pattern of steady behaviour. In addition, Rastogi in Bulus (1990) defined a counsellor as "one who helps the client to explore his feelings, take appropriate decisions, and initiate new actions to resolve problems".

The counsellor is a patient listener, he/she knows how to encourage client and gives reassurance, and he/she has a deep understanding of human motives. This definition presents the counsellor as one who makes every effort to be very close to students in order to direct and modify their behaviour towards useful purpose.

\section{Planning Effective Study Habit Programme}

Parents send their children to school to learn. In the school, children are exposed to various experiences which influence their behaviour. Therefore, learning is a change in behaviour. Such a change is seen in their mental reasoning, physical growth, manipulative skills and development of values and interests. The change may be easy or difficult depending on the home and the school environment.

Studying presents problems to students in various forms. Some students have the eagerness to study but may not know the strategies to study effectively. Students from this group can benefit if an effective study programme is organized in the school. A planned programme of study is a good strategy to motivate students to explore, ask questions and solve problems that confront them.

Among the objectives of education is the clause "the need to help the individual to develop his/her full potentials". This cannot be achieved without a proper planning to make students develop positive attitudes towards learning, one of the reasons for having a good study programme in the school environment. Providing a study programme is an important strategy for school management. In actual fact it helps a child to make intelligent choice and adjustment.

As we all know, adolescence is a turbulent stage of growth and students are prone to make many mistakes if they are not controlled or directed. A good plan for studies is necessary and students should learn to use their time profitably for the benefit of the school and themselves. A well planned study programme gives students the freedom to pursue their interests in school subjects and such freedom leads to the development of their personalities. During this study period, individuality is developed and recognized. 


\section{A Typology of Study Habits}

There are some known study/reading habits which have either positive or negative orientation. For the purpose of this topic, they are grouped into:

(i) Hobbial

(ii) Recreational

(iii) Concentration

These ones produce positive effects while

(iv) Deviational has a negative effect.

\section{(i) Hobbial}

A hobby is an activity one does because he derives some joy and satisfaction in doing it. After formal education attainment, some people like reading as their hobby. Its purpose is to widen the reader's horizon in things educational, religious, political, economic, current affairs, fiction and non-fiction. The practice of reading as a hobby makes one to be versatile in knowledge in many areas and the person can discuss knowledgeably with others. This type of reading is a positive one to learning not only in developing mental reasoning but also in helping the person to satisfy his interests and aspirations.

\section{(ii) Recreational}

Fundamentally, reading for recreation or relaxation is very common among the education elite. People who have gainful employment spend the whole day in the offices trying to solve problems related to the jobs they do. When they come back from work, they normally desire a change by reading books newspapers and other written materials which are different and of interest to them. Students should be encouraged to read magazines instead of reading text books all the time. Students, who read magazines at intervals learn to relax, cool their brain and avoid mental fatigue. This type of studying produces positive results as it keeps the student's interests, helps them to acquire more knowledge and makes for a disciplined life in the school. In most cases, its effect in inducing sleep and rest after tedious reading in the classroom or the library adds to good health habits. 
(iii) Concentration: the concentration reading is not positive but it is the most important one that provides the desired outcome. It is the bedrock and the result oriented reading which makes for achievement. Researches by eminent scholars of language arts have come up with several formulae for effecting positive results in a learning situation. These include the S4R, Unoh (1974) Robinson's (1961) SQ3R and Rosemary "L" method (Ogbodo: 2005), recommended for use in school by counsellors.

The techniques are:

\section{(a) SQ3R Technique:}

S-Stands for survey, which means having a bird's eye view of the contents, chapters, going through the headline and sub-headings to the end in order to have a general impression of the written material.

\section{Q-Stands for Question:}

This demands that on the basis of general impression of the material to be read, the reader should formulate question on the broad ideas he has grasped from the general, survey in anticipation of likely author's answers. These question are formulate mentally as stimulating areas for further of paper for later reference.

\section{R1-(i.e. first R) Means Read:}

Read the chapter or passage carefully to pick out answers to the questions which were formulated. In this context, concentration is the watch word, as one has to avoid all forms of distractions. In the course of the reading, one has to look for answer to the questions.

\section{R2-(i.e. the second R), Means Recite:}

The reader is required to recite to himself or to a friend or to write down all the salient points he shifted from the passage. The ability to be this is a good proof of understanding of the passage. Students should be encouraged to repeat the, facts several times.

\section{R3-(i.e. Third or last R) Means Review or Revise:}

At the end of the four steps above, the reader should go over the passage for better and more permanent understanding of the passage read. He should attempt to answer the questions he formulated in step two above. This could be achieved by going through the notes on the 
margin, underlined sentences and phrases. Re-reading the passage carefully to answer the questions for the sake of a better understanding of the passage means actually studying. Revision may be resumed periodically so as to keep the details fresh and familiar in the memory, and to be used when required like in an examination.

(b) The Rosemary (L):-

This is another useful reading/study method and is most suitable to study large materials, the study of difficult material and for preparation for tough examinations like the Senior Secondary Certificate Examination (SSCE), Junior Secondary School Certificate Examination (JSSCE), General Certificate of Education (GCE), O/A, level, Degree examinations, etc. This method is use in higher institutions of learning etc. The method calls for distributed learning and distributed practice. Try to take each chapter, section or subunit one after another at a time.

Explanations of ROSEMARY (L)

R:- Repetition: you read the material over and over again, re-read many times as you can to make it completely familiar and get used to the words inside the material or topic(s) treated.

$\mathbf{O}=$ Over-Learning:-Here, the repetitive reading and re-reading again and again will produce over-learning of the material to the extent that if you have to forget any part, that part will be minimal.

S= Summarization: - For effective study habit, let your summary be short and straight to the point.

$\mathrm{E}=$ Enumeration: - this is a follow up to the last step; enumerate the major points in a linear manner, the most important points coming first. You can write them down so that you will not forget.

M=Mnemonics: Devise mnemonics for important ideas, principles, concepts, formulae etc. This is to help your immediate recall and reutilization of such ideas, formula etc. 
A = Application: - Apply the material learnt to your personal life and daily

$\mathbf{R}=$ Revision:- Revise all you have done up to this stage. Give yourself thorough revision, bringing every thing learnt to memory

Y= Yes:- I know it now! I can apply it to any situation of my life to impact my world.

You can now use the (L)

L Means linkage: This means you link the materials read to practical daily living to enable you internalise the facts.

\section{(IV) Deviational:}

The reader deviates from the actual reading and pretends to be reading. If this habit is not curbed in students, it may lead to loss of interest in the acquisition of knowledge. Studying or reading textual materials by this method takes the form of Brown study or Browsing. Result of this type of reading is a negative one because the person deviates from the norms and rules of actually studying.

(a) Brown Study:

In this context, the mind of the reader wanders away when he opens a book. He looks at the print without actually grasping anything. Looking refers to the physical use of the facial structure in a particular direction, in the case of the book as target for the looking. On the other hand, seeing connotes the extra application of the eye as one looks.

Focus is necessary if the use of the eye will be meaningful. The ocular nerves are employed in order to use what one looks at, for the brain to pick the message for future use if necessary. Brown study depicts deceit of oneself. Students should be advised to change to recreational reading immediately the mind begins to wander away while one is reading.

(b) Browsing:

This practice refers to reading of a material without any definite plan or interest. In is also known as glancing through. This type of reading is common among people who saunter into a bookshop or a public library and pick up printed materials to see if there is anything of interest. For example, one can browse through 
newspapers and magazines to pick up some worthy news by a quick glance through headlines or sub headline. In such a case it may produce a positive result as one becomes interested and decides to buy or borrow such printed material.

However, deviational studying habits by students are a defence mechanism to satisfy parents and teachers. Deviational studying in all its forms result in learning malpractices, failure in examinations, learning frustrations, loss of self-concept, school drop-out etc. Teachers and school counsellors should watch out for this type of negative studying habit among school children.

\section{Techniques For Effective Study Habit Formation}

Students should be encouraged to acquaint themselves with the following as a means to achieve better results. These questions would help to direct their attention to useful areas. According to Bakare (1971)

\section{Scheduling:}

i. Do you usually arrive at the class a few minutes ahead of time?

Punctuality they say "is the soul of business".

ii. Do you devote sufficient time to each of your subjects?

iii. Do you make your schedule sufficiently flexible so that you are able to make necessary adjustments?

iv. Do you include rest, relaxation and social activities in your schedule or timetable?

v. Do you avoid activities which tend to interfere with your schedule?

\section{Working condition:}

i. Do you use the same room and the same part of the room when you study?

ii. Do you have adequate light in your study place?

iii. Do you have periodic examination for visual and other physical defects?

iv. Do you usually have everything required for the task at hand when you begin to study?

\section{Concentration:}

i. Do you clear the top of the desk of distracting objects?

ii. Do you start to study immediately rather than wait for the mood to strike you?

iii. Do you vary your study technique sometimes, in order to increase concentration? 


\section{Learning:}

i. Do you distinguish reading between important and unimportant points?

ii. Do you give adequate attention to why and how, instead of limiting your scope to what, who, when and where?

iii. Do you set a goal to be reached before starting your study?

iv. Do you relate the materials learned in one course to the materials in other subjects?

v. Do you learn well whatever you attempt to learn?

\section{Reading:}

i. Do you look for something definite when you read?

ii. Do you pay close attention to the charts, maps, tables, graphs diagrams, illustrations, and figures when you read?

iii. Do you find that you are able to keep up with your reading assignment and read selected magazine and newspapers?

iv. Do you relate accurately that which you have read?

\section{Note-taking:}

i. Do you think about your later use of the notes when you are taking them?

ii. Do you underscore important points and write in the margins of your textbook?

iii. Do you select, evaluate, and summarize the main points from the voluminous materials presented?

iv. Do you take notes on supplementary reading materials?

\section{Taking Examination:}

i. Do you have a feeling of calm immediately prior to a scheduled examination?

ii. Do you try to imagine examination question during your preparation for examination?

iii. Do you usually feel confident that you are prepared before taking an examination?

iv. Do you take time to understand the examination questions thoroughly before starting to answer?

\section{Teacher consultation:}

i. Do you find it easy to consult a subject-master/mistress when you have difficulty with his/her subject?

ii. Do you ask a teacher for further explanation on a point that is not clear to you? 


\section{Guideline For Private Time-Table}

1. Each student should have a private time table. The daily study could be divided into three periods per day. Subjects should be arranged in terms of relative importance. The best study time covers:

\begin{tabular}{lll}
\hline Morning & Afternoon & Evening / Night \\
\hline $4-6.00$ & $3.30-4.30$ & $8.00-10.30$ \\
\hline $\mathrm{Am}$ & $\mathrm{Pm}$ & $11(\mathrm{pm})$ \\
\hline
\end{tabular}

2. If one's ability to study and concentrate effectively lasts one hour or less, the time has to be plotted within these time rages. Those in the boarding house must have to be guided by the school schedule.

3. One day must be left open as a free day from studying.

4. Rest periods must be included at their appropriate spaces. The most suitable time is usually between $2 \mathrm{pm}$. and $4 \mathrm{pm}$.

5. Time for social activities, physical education and evening time for watching the television has to be indicated as a controller and regulator of each student's behaviour towards achieving the set goal. The time table has to be reviewed and adjusted at the end of each term.

\section{The School Counsellor's Role}

For the purpose of creating a conducive and healthy atmosphere in the school, the counsellor's work can be divided into two broad headings: General and Specific areas

\section{A. General Roles:}

His general role is in the area of planning, co-coordinating and referral. He, in consultation with the school principal, plans for the following:

\section{i. Orientation Programme for New Students :}

This is necessary to enable them cope with the number of subjects on the time table and develop, as early as possible, the right attitude towards secondary education. After the initial orientation, the subsequent programmes will be to remind them of the importance of effective study habit. Apart from consulting the principal of the school, the counsellor has to inform other teachers and to solicit their 
assistance for the orientation. Teachers can give short and general ideas about their area of specialization.

ii. Open Seminar for Various Classes:

The time-table has to be made in such a way that two classes may be reached at a time. For example, classes V \& VI, III \&II and Class I alone at different at time. The counsellor also plans the details of the programme, works out how long the seminar will last, the sequence, and the topics relating to effective study habit.

iii. Follow-up Visits:

The time for preparation classes should be arranged and organized to check lapse in good study habits:

iv. Referral:

The counsellor can direct referral cases to other specialists for proper assistance. A child with speech or health problems can be sent to doctors-concerned. Students with subject problems should be referred to the specialist teachers.

B. Specific Roles:

A counsellor is a teacher, an enabler and an advocate. An enabler is "one whose activities are directed towards assisting the client to find the coping strength and resources within himself" for the changes necessary for accomplishing the set objectives. On the other hand, an advocate is one who acts as a "spokesman for the client by presenting and arguing the client's course when it is necessary, to accomplish the set objective" (Compton and Gall away 1975 in Ogbodo (2004).

The above statements imply that the counsellor has to help students to assess their reading ability, aptitude and help them through planning to develop effective study habits. Consultancy should be client-centred as the counsellor applies confidentially. The counsellors should speak to other teachers on behalf of the students where the need arises. He should also help the students to find some motivating factors that will spur them to real achievement.

\section{Conclusion}

The formation of effective study habit in school is an outcome of good guidance and counselling program. Students who are well guided and counselled are result oriented, thus participating in all tests and 
examinations. The formation of effective study habit will create the awareness for regular and steady learning.

\section{References}

Adams R.(1974).Reading Skill, A guide for better reading , New York, John Wiley and sons.

Akinboye, J. O. (1980) How to study and pass important examinations, Ibadan maritime printers

Armbruster, Bonnie B etc. al, (1993), The role of meta-cognition in reading to learn, a development perspective reading education report no .40

Barkare C. M. G (1971) study Habit inventory. University of Ibadan press.

Bulus I. (1990) ; Guidance practice in schools, Jos, Ehindero, Nig. Ltd.

Cooker S.D (1966) intensive English for senior secondary schools improving comprehension, Blostion Houghton Miptin Company.

Chukwu .S. (1987); Guidance and counselling for Teachers 'new African Publishing company Owerri Nigeria

Coles, M. \& white, C. (1982), how to study and pass examinations, Collins Education.

Edward F. (1974); Teaching Faster Reading, Cambridge University Press.

Ogbodo R.O (2002) Effective study Habits and examination guide for students, Gracehand publishers Abuja.

Owuanam T. (2007); handbook of guidance and counselling, Bolabay publishing, Lagos, Nigeria. 